\title{
Herniated Gravid Uterus: Clinical Course and Result of Treatment
}

\author{
J. G. Makama ${ }^{1}$, V. I. Odigie ${ }^{1}$, L. M. D. Yusufu ${ }^{1}$ and N. Ameh ${ }^{2}$ \\ ${ }^{1}$ Division of General Surgery, Department of Surgery, Ahmadu Bello University Teaching Hospital, \\ Shika-Zaria, Nigeria \\ ${ }^{2}$ Department of Obstetrics and Gynaecology, Ahmadu Bello University Teaching Hospital, Shika-Zaria, Nigeria \\ Reprint requests to: DR. J. G. Makama, Department of Surgery, A. B. U. Teaching Hospital, Shika-Zaria, \\ Nigeria.E-mail:_jerlizabeth@yahoo.com
}

\begin{abstract}
Herniated gravid uterus in an incisional hernia of the anterior abdominal wall is relatively rare. A 30 year-old house wife presented with a six month gravid uterus that had herniated through an incisional hernia of the anterior abdominal wall. She had non-operative management till term, when she then had elective lower caesarian section. Physiotherapy of the anterior abdominal wall muscles to improve their tone was done. She subsequently had keel's repair of the hernia. Aggressive physiotherapy of the anterior abdominal wall muscles followed by keel's repair may be an alternative surgical technique in patients with a moderate defect of incisional hernia.
\end{abstract}

Key words: Pregnancy, hernia, surgery

\begin{abstract}
Résumé
Utérus de la gravide hernie dans une hernie incisionale de la paroi abdominale antérieure, est relativement rare. Une femme âgée de 30 ans s'est présentée atteinte d'un utérus gravide d'une durée de six mois, qui avait hernie à travers une hernie incision ale de la paroi abdominale antérieure. Elle avait non traitement opératoire au terme quand elle avait eu la césarienne élective dans le membre inférieur. La physiothérapie de la paroi abdominale antérieure des muscles a été opérée afin d'améliorer leur tonalite. Elle avait ensuite subi à la réparation du genou de l'hernie. Une physiothérapie agressive de la paroi des muscles abdominale antérieure survie par la réparation du genou peut être une intervention chirurgicale alternative chez les patients atteints d'une anomalie légère d'hernie incision ale.
\end{abstract}

Mots-clés: Grossesse, hernie, chirurgie

\section{Introduction}

Incisional hernia of the anterior abdominal wall in women is not rare. ${ }^{1-3}$ However, herniated gravid uterus through an abdominal incisional hernia is uncommon. ${ }^{4,5}$ Potentially, grave obstetric risks to the fetus and the mother such as incarceration, ${ }^{5}$ strangulation $^{5,6}$ rupture of lower uterine segment, ${ }^{7}$ skin ulceration may result. ${ }^{5-7}$ It is thus a hazardous condition and needs timely intervention before these complications occur. ${ }^{8} \mathrm{We}$ report our experience on the clinical course and out come of management of a pregnancy that herniated through an anterior abdominal wall incisional hernia.

\section{Case report}

A 30-year-old woman who was para ${ }^{4+0}$ was referred to our hospital from a general hospital with a year history of abnormal bulge of the anterior abdominal wall. She had had an emergency caesarian section for an obstructed labor and fetal distress in the same hospital a year prior to presentation. During that admission she had a prolonged post operative period due to surgical site infection which was treated nonoperatively by oral antibiotics and daily wound care.

On presentation, her complaint was discomfort and dragging sensation with a huge bulge of the mid lower abdomen at the surgical site and was 24 weeks pregnant.

Physical examination showed a short-stature woman, well nourished and not pale. She was afebrile with a temperature of $37.2^{\circ} \mathrm{C}$. The cardiopulmonary status was normal with a pulse rate of 82 , blood pressure of $120 / 76 \mathrm{mmHg}$ and lung fields were clear. The lower abdomen was distended, with a midline hypertrophic scar. There was a fascia defect of $20 \times 30 \mathrm{~cm}$ at the same site harbouring an incisional hernia with herniated gravid uterus (Figure 1). The fundal height was 26/52 size and fetal parts were felt 
through the defect on the anterior abdominal wall.

Hemogram and urine examination were normal. Pelvic ultrasonography revealed the uterus to have herniated in the incisional hernia and a single live fetus in longitudinal lie with a normal situated placenta. The abdominal discomfort and dragging sensation necessitated hospital bed rest. She was monitored for daily fetal movement and heart rate with a fetoscope and weekly ultrasound until 38th week gestation when satisfactory growth had occurred. She consented to elective lower segment caesarian section with bilateral tubal ligation, which was effected. She was delivered of a live female baby weighing $3.0 \mathrm{~kg}$. The lateral walls of the uterus were very adherent to the neck of the hernia and the anterior abdominal wall muscles were flabby and so repair of the hernia was not feasible at that time. Post operatively both mother and child did well and were discharged to the surgical follow up clinic. In the surgical outpatient Department, she had aggressive physiotherapy of the anterior abdominal wall muscles for 6 months following which the muscles regained good tone and strength. Subsequently, she had Keel's repair of the hernia, did well post operatively and went home on the 10th postoperative day. On follow up after 4 months of discharge she had no complaint and was doing well.

Figure 1. Incisional hernia with a herniated gravid uterus

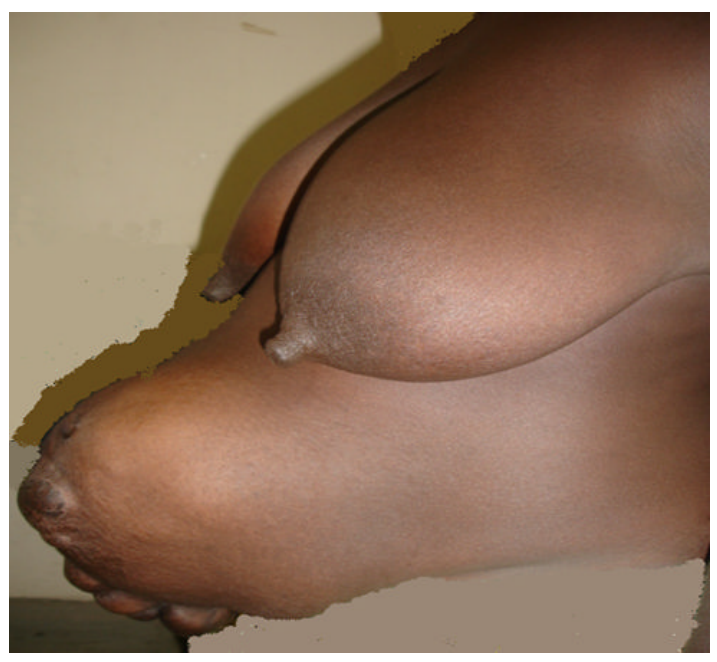

\section{Discussion}

The incidence of anterior abdominal wall incisional hernia varies between $5 \%-15 \%^{1,2,4}$ while caesarian section accounts for $3.1 \%{ }^{1,5,8}$ The presence of a pregnant uterus in an anterior abdominal wall incisional hernia may pose a serious obstetric situation necessitating emergency reduction. ${ }^{5,9}$ Herniated gravid uterus may cause ulceration on anterior abdominal wall, pre term labor, ${ }^{2}$ intra uterine growth restriction, accidental hemorrhage, strangulation, intrauterine fetal death, rupture of the lower uterine segment, post partum hemorrhage, dysfunctional labor, all of which are possible complications. $^{2,5,8,10,11}$ The patient in this report did not have any of these complications, probably because she presented early in pregnancy and had the chance to be managed properly.

The management of incisional hernia in pregnancy is mainly conservative. ${ }^{5,12}$ The uncertainty about wound integrity of anterior abdominal wall and uterus during vaginal birth in these patients with a previous caesarian section has lead most obstetricians to favor an elective caesarian section as the safest mode of delivery. ${ }^{5}$ Our patient had an elective lower segment caesarian section. Post partum elective herniorrhaphy is usually the norm. ${ }^{2}$ This is because overstretched abdominal wall may interfere with proper repair and associated risk of wound disruption and infections may be high. ${ }^{8}$ However, incarceration or burst abdomen will necessitate an antenatal herniorrhraphy.

Hernia repair can be done during the operation of caesarian section, if patient is fit, while delayed mesh repair after $6-8$ weeks ${ }^{5}$ is another option. However, in regions with scarce medical facilities and a huge defect, keel's repair may be offered as an alternative method after an aggressive physiotherapy of the abdominal wall muscles. Little has been reported about the fate of the abdominal wall subjected to further pregnancies following repair of ventral hernias. ${ }^{2,13}$ However, this patient consented to bilateral tubal ligation because she was multiparous and did not wish to undergo any more psychosocial trauma of pregnancy, so she is unlikely to become pregnant again.

\section{Conclusion}

Herniated gravid uterus in an incisional hernia sac is a delayed but rare complication of an abdominal wall closure especially in women of child bearing age; aggressive physiotherapy of the anterior abdominal wall muscles and then keel's repair is an alternative surgical technique for such wide defects in developing countries.

\section{References}

1. O'Dwyer PJ, Courtney CA. Factors involved in abdominal wall closure and subsequent incisional hernia. Surgeon. 2003;1:17-22.

2. Dare O, Lawal OO. Experience with 29 cases of female ventral incisional hernia in Ile Ife, Nigeria. Int J Gynaecol Obstet. 1991;36:29-32.

3. Yusufu LMD, Odigie VI. Incisional hernia. Trop Doct. 2004;34:62.

4. Sahul A, Bupathy A. Evisceration of pregnant uterus through incisional hernia site. J Obstet Gynaecol Res. 2006;32:338-340.

5. Rao Radha S, Shankaregowda HS. A case of herniated gravid uterus through a laparatomy 
scar. Indian J Med Sci. 2006;60:154-157.

6. Malhotra M, Sharma JB, Wadhwa L, Arora R. Successful pregnancy outcome after caesarian section in a case of gravid uterus growing in an incisional hernia of the anterior abdominal wall. Indian J Med Sci. 2003;57:501-503.

7. Deka D, Banerjee N, Takkar D. Incarcerated pregnant uterus in an incisional hernia. Int $\mathrm{J}$ Gynaecol Obstet. 1990;32:377-379.

8. Adesunkami AR, Faleyinmu B. Incidence and aetiological factors of incisional hernia in a post caesarian operation in a Nigerian hospital. J Obstet Gynaecol. 2003;23:258-260.

9. Ray KK, Aggarwal S, Banerjee K, Kumar S,
Chanana C. Gravid uterus in an incisional hernia leading to burst abdomen. Int J Gynaecol Obstet. 2005;5:2-5.

10. Fullman PM. An incisional hernia containing an incarcerated twin pregnant uterus. Am J Obstet Gynecol. 1971;111:308-309.

11. Dare FO, Makinde OO, Lawal OO. Gravid uterus in an anterior abdominal wall hernia of a Nigerian woman. Int J Gynaecol Obstet. 1990;32:377-379.

12. Banerjee N, Deka D, Sinha A, Prasrad R, Takkar D. Gravid uterus in an incisional. J Obstet Gynaecol Res. 2001;27:77-79.

13. Abrahamson J, Gorman J. Pregnancy and ventral hernia. Hernia. 2000;4:187-191. 